\title{
RAPD Based Assessment of Genetic Diversity of Adhatoda vasica Leaves from Different Sub- Continents of India
}

\author{
Madhukar Garg1', Ennus Tajuddin Tamboli', Mhaveer singh'1, Karishma Chester', Malik Zainul Abdin², \\ Ruby Chandna ${ }^{2}$, Sayeed Ahmad ${ }^{1}$
}

'Bioactive Natural Product Laboratory, Department of Pharmacognosy and Phytochemistry, Faculty of Pharmacy, Jamia Hamdard, Hamdard University, Hamdard Nagar, New Delhi -110062, India

${ }^{2}$ Department of Biotechnology, Faculty of Science, Jamia Hamdard, Hamdard University, Hamdard Nagar, New Delhi -110062, India

\begin{abstract}
The present work assessed the genetic divergence amongst the accessions of vasaka collected from different sub-climatic zones of India by RAPD (Randomly Amplified Polymorphic DNA) using twenty random declaimer primers (OPA 1-OPA 20) as the plant was found to enjoyed its therapeutic efficacy in Ayurvedic and traditional system of medicines. The dendrogram constructed for cluster analysis using an un-weighted pair group method with arithmetic means (UPGMA) grouped the accessions into 2 major clusters based on win boot. Out of the twenty random primers used for studying genetic divergence sixteen primers were found to be polymorphic. Out of 20 primers 3 were found to be $100 \%$ polymorphic generating a total of 313 amplification products with an average of 19.5 products per polymorphic primer. Genetic relationships among accessions were evaluated by generating a similarity matrix based on Jaccard's co-efficient ranging from 0.60 to 0.91 . Results showed that both environmental and genetic factors were effective in observing variations. The degree of genetic variations detected among the accessions of vasaka suggested that RAPD approach seemed to be best suited for assessing with high accuracy the genetic relationships among distinct $A$. vasica accessions.
\end{abstract}

Key words: RAPD, Genetic diversity, Adhatoda vasica, variation, Polymorphism, Primer.

\section{INTRODUCTION}

Adhatoda vasica (Acanthaceae) commonly known as vasaka, Malabar nut tree in English and arusa or adulsa in local Hindi language ${ }^{1}$ is a primary herb of Ayurvedic system of medicines and has been used in indigenous in India for over last 2000 years. A. vasica is a medium sized shrub found up to an altitude of $1300 \mathrm{~m}$ distributed throughout tropical and temperate regions. ${ }^{2}$

Leaves of $A$. vasica are generally administered in yogic practices to clear the respiratory passages as well as in the preparations including cough syrups. ${ }^{3}$ They were reported to contain the quinazoline alkaloids vasicine, vasicinone and deoxyvasicine. ${ }^{4}$ Some of the chemical compounds found in the leaves and roots of this plant includes essential oils, fats, resins, sugars, gums, amino acids, proteins and vitamin C. ${ }^{5}$
Since a vast majority of medicinal plants have been recklessly exploited to a greater extent so it makes sense to rationalize the use of some important medicinal plant through screening and validation of germplasm. In the present research work it will be prudent to evaluate the genetic component in A. vasica for conservation and management of genetic diversity as the species has been included in the list of endangered and threatened species of India over a decade. ${ }^{6}$ The Indian sub-climatic zones plant specialist group has also identified $A$. vasica for the detailed study and protection along with other species like Abrus precatorius Linn. Costus speciosus, Centella asiatica (Linn.), Gloriosa superb Linn. Ramwolfia serpentina Benth. ex Kurz., Saraca indica de Wilde, Streblus asper Lour., Tribulus terrestris L. and Withania
Submission Date :25.07.2014 Revision Date $\quad: 14.10 .2014$ Accepted Date : :07.01.2015

DOI: 10.5530/ijper.49.3.9 Correspondence Address Dr. Sayeed Ahmad Bioactive Natural Product Laboratory, Department of Pharmacognosy and Phytochemistry, Faculty of Pharmacy, Jamia Hamdard, Hamdard University, Hamdard Nagar,

New Delhi-110062, India Phoneno: +919891374647 E-mail:sahmad_jh@yahoo. co.in

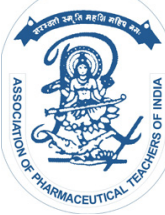

www.ijper.org 
somnifera linn.) Dunal. ${ }^{7}$ Moreover, frequent adulteration of vasaka leaves with Alianthus beddomei (Clarke), $A$. altissimia (Mill) Swingle. A.glandulosa (Desf) and A. excelsa Roxb. Leaves ${ }^{8}$ has also made the condition even worsened as did the Traditional Chinese Medicines (TCM) contaminated with Aristolochia causing an epidemic of sub-acute intestinal nephropathy and necessitating kidney transplantation of the users in Belgium ${ }^{9}$ therefore further necessitating the need for the proper identification and conservation of the particular plant species $A$. vasica.

To combat the mentioned difficulties the present research was aimed to establish the level of genetic relatedness between the different accessions of $A$. vasica by RAPD so as to identify and maintain the efficacy of the plant. The technique chosen is a PCR based simple, reliable and cost effective technique and acting as a powerful tool for the analysis of plant genome ${ }^{10}$ in comparison to other molecular techniques i.e. AFLP (Amplified Fragment Length Polymorphism) RFLP (Restricted Fragment Length Polymorphism), SSR (Simple Sequence Repeat) SCAR (Sequence Characterized Amplification Regions) VNTRs (Variable Number of Tandem Repeats) and non- PCR based Restriction hybridization Techniques employing the use of restriction end nucleases and Hybridization methods ${ }^{11}$ as it is simple to operate and does not involve radioactive labelling. ${ }^{12}$ The RAPD technique requires a very low amount of genetic material and provides more of the detailed genetic information due to either increased variability of loci or the greater no of available loci. In addition it has been used to identify polymorphism for elicit information on divergence, variation, diversity analysis, phylogeny, quantitative traits, marker assisted selection etc. ${ }^{13}$

\section{MATERIALS AND METHODS}

\section{Plant material}

In the present study genetic diversity was analysed using RAPD primers among the different accessions of vasaka collected from different geographical locations of India. A definite criterion was adopted for the collection of the samples as the collection of young leaves was carried out in the month of March under flowering conditions from various sub-climatic zones at different altitudes from various geographical locations and transferred in a laboratory in an ice-box and stored at $-20^{\circ} \mathrm{C}$. The collection sites included viz. New Delhi (1) Hisar (2) Kurukshetra (3) Nahan (4) Chandigarh (5) Banaras (6) Solan (7) Dehradun (8) Patiala (9) Dalhousie (10). The study was conducted at Bioactive Natural Product Laboratory, Jamia Hamdard, New Delhi, located at $77^{\circ}$ (longitude) and $28^{\circ} 8^{\circ}$ (latitude). The plants collected were identified by Dr. Altaf ahmad, Taxonomist in Department of Botany and deposited the voucher specimen in Department of Pharmacognosy and Phytochemistry, Jamia Hamdard, New Delhi, India.

Ten cultivars of $A$. vasica were utilized to carry out the present study. The accessions numbers and codes given to these cultivars were mentioned in Table 1.

\section{Reagents and chemicals}

The chemicals and reagents used in the isolation of DNA were

CTAB extraction buffer $[2 \%(\mathrm{w} / \mathrm{v})$ CTAB; $20 \mathrm{mM}$ EDTA, pH 8.0; 100 mM Tris-HCl, pH 8.0; 1.4 M NaCl]; CTAB $/ \mathrm{NaCl}$ solution $[10 \%(\mathrm{w} / \mathrm{v})$ CTAB; $0.7 \mathrm{mM}$ $\mathrm{NaCl}]$; CTAB precipitation solution $[1 \%(\mathrm{w} / \mathrm{v}) \mathrm{CTAB}$; $50 \mathrm{mM}$ Tris-HCl, pH 8.0; 10 mM EDTA]; High salt TE buffer [10 mM Tris-HCl, pH-8.0; 0.1 M EDTA, pH 8.0; $1.0 \mathrm{M} \mathrm{NaCl}$; TE buffer [10 mM tris-HCl, $\mathrm{pH}-8.0$;

\begin{tabular}{|l|c|c|c|c|}
\hline \multicolumn{5}{|c|}{ Table 1: A. vasica accessions from different sub-climatic zones sampled for RAPD } \\
\hline \multicolumn{1}{|c|}{ Acc. Code } & Place of collection & Latitude (N') & Longitude (E') & Altitude (m) \\
\hline AVND & New Delhi & $28^{\circ} 63^{\circ}$ & $77^{\circ} 22^{\circ}$ & 305 \\
\hline AVHR & Hisar & $29^{\circ} 9^{\circ}$ & $75^{\circ} 43^{\circ}$ & 221 \\
\hline AVKU & Kurukshetra & $29^{\circ} 58^{\circ}$ & $76^{\circ} 53^{\circ}$ & 260 \\
\hline AVNH & Nahan & $30^{\circ} 33^{\circ}$ & $77^{\circ} 21^{\circ}$ & 932 \\
\hline AVCH & Chandigarh & $30^{\circ} 43^{\circ}$ & $76^{\circ} 47^{\circ}$ & 321 \\
\hline AVBS & Banaras & $25^{\circ} 22^{\circ}$ & $83^{\circ} 00^{\circ}$ & 81 \\
\hline AVSN & Solan & $30^{\circ} 90^{\circ}$ & $77^{\circ} 09^{\circ}$ & 1445 \\
\hline AVDN & Dehradun & $30^{\circ} 19^{\circ}$ & $78^{\circ} 04^{\circ}$ & 1880 \\
\hline AVPL & Patiala & $30^{\circ} 20^{\circ}$ & $76^{\circ} 24^{\circ}$ & 252 \\
\hline AVDL & Dalhousie & $32^{\circ} 38^{\circ}$ & $75^{\circ} 58^{\circ}$ & 2040 \\
\hline
\end{tabular}


1.0 mM EDTA, pH 8.0]; Chloroform: Isoamyl alcohol (24:1,v/v); Iso-propanol; Absolute ethanol : $80 \%$ ethanol; 2-Mercaptoethanol (2 ME); Liquid nitrogen

\section{DNA extraction (Isolation of DNA by CTAB method)}

Five hundred micro litres of CTAB extraction buffer was heated to $65^{\circ} \mathrm{C}$ followed by the addition of 2- mercapto-ethanol $(10 \mu \mathrm{l})$ to this mixture just before the extraction process. $0.5 \mathrm{~g}$ of fresh plant material and $100 \mathrm{mg}$ of dried sample were frozen in liquid nitrogen $\left(-196^{\circ} \mathrm{C}\right)$ in a sterile mortar and grounded to a fine powder. The ground frozen tissue was incubated at $65^{\circ} \mathrm{C}$ for $1 \mathrm{~h}$ in a water bath and mixed uniformly by gentle inversion. Chloroform: Isoamyl alcohol $(24: 1, \mathrm{v} / \mathrm{v})$ was added in equal volume to the homogenate and mixed gently by inversion, followed by centrifugation at 10,000 rpm $(7500 \times \mathrm{g})$ for 15 minutes. The upper phase was pipette into a sterile eppendorff tube. This step was repeated twice with addition of $10 \%$ CTAB in second repeated step. One volume of CTAB precipitation solution heated at $65^{\circ} \mathrm{C}$ was added to the recovered supernatant. A precipitate was formed at this stage and mixture got centrifuged at $2700 \mathrm{rpm}(500 \times \mathrm{g})$ for $5 \mathrm{~min}$. DNA pellet was recovered by decanting the supernatant. The DNA pellet was dissolved in $500 \mu$ l of high-salt buffer. The DNA was then precipitated by keeping for an hour and then centrifuged for $15 \mathrm{~min}$ at 10,000 rpm (7500 $\times \mathrm{g})$. The DNA pellet was recovered by decanting the supernatant followed by washing in $80 \%$ ethanol and $90 \%$ ethanol. After drying, the pellet was re-suspended in TE buffer and stored at $-20^{\circ} \mathrm{C}$ till further use.

\section{DNAquantificationandagarosegelelectrophoresis}

The quantification of genomic DNA was achieved using a spectrophotometer (UV- Visible spectrophotometer, Shimadzu, Japan). The yield was determined by measuring the absorbance at 260, 280 and $320 \mathrm{~nm}$. The level of DNA purity was determined by the ratio of absorbance obtained at 260/280 $\mathrm{nm}$.

Agarose gel $(1.2 \%)$ was prepared by dissolving appropriate amount of agarose in $0.5 \mathrm{X}$ TAE buffer. DNA sample and DNA loading dye were mixed in 5:1 ratio for each weal and loaded with the help of micropipette. Electrophoresis was conducted at 90 volts for $1 \mathrm{~h}$ in 0.5 $\mathrm{X}$ TAE buffer. The $\mu$ gel was then stained with ethidium bromide solution $(0.5 \mu \mathrm{g} / \mathrm{ml})$. After de-staining in distilled water, the gels were viewed and stored in gel documentation system (alpha imager EC).

\section{RAPD-PCR analysis}

A total of 20 random decamer primers (custom synthe sized by Banglore Genei Pvt. Ltd., GCs content > 50\%) were used for RAPD analysis. DNA amplification reactions were performed in $15 \mu \mathrm{l}$ reaction volumes $(2.5 \mu \mathrm{l}$ PCR buffer with $\mathrm{MgCl}_{2}, 1.5 \mu \mathrm{l}$ dNTPs, $1.0 \mu \mathrm{l}$ primer, $1.0 \mu \mathrm{l}$ Taq DNA polymerase, $1.0 \mu \mathrm{l}$ DNA template and $8.0 \mu \mathrm{l}$ of milli Q water) (Table 2). Amplification reaction was carried out in a Bio-Rad Thermal cycler with a following thermal profile comprising of one cycle of 2 min at $94^{\circ} \mathrm{C}$ (initial denaturation) followed by 38 cycles of $30 \mathrm{sec}$ at $92^{\circ} \mathrm{C}$ (denaturation), $60 \mathrm{sec}$ at $32^{\circ} \mathrm{C}$ (primer annealing) and $90 \mathrm{sec}$ at $72^{\circ} \mathrm{C}$ (final extension) which

\begin{tabular}{|c|c|c|c|c|}
\hline Parameters/Reagents & $\begin{array}{c}\text { Optimized } \\
\text { concentrations }\end{array}$ & Tested range $(\mathrm{U})$ & Volume used $(\mu L)$ & Remarks \\
\hline $\begin{array}{l}\text { PCR buffer with } \mathrm{MgCl}_{2} \\
(\mathrm{mM})\end{array}$ & $15 \mathrm{mM}$ & $1-5$ & 2.5 & $\begin{array}{l}\text { Deviation increased non- } \\
\text { specificity and affected } \\
\text { yields of products }\end{array}$ \\
\hline $\begin{array}{l}\text { Deoxy-nucleotide } \\
\text { triphosphate (mM) }\end{array}$ & $2.5 \mathrm{mM}$ & $0.2-1.4$ & 1.5 & $\begin{array}{c}\text { Increased concentration } \\
\text { reduces free } \mathrm{Mg}^{2+} \text { ion } \\
\text { which interferes with } \\
\text { enzyme }\end{array}$ \\
\hline $\begin{array}{l}\text { Primer concentration } \\
\text { (10 pmol/ } \mu \mathrm{L})\end{array}$ & $10 \mathrm{pmol}$ & $0.1-1.5$ & 1.0 & $\begin{array}{l}\text { Lower concentration } \\
\text { leads to absence of } \\
\text { amplification whereas } \\
\text { higher concentration } \\
\text { leads to dimer formation }\end{array}$ \\
\hline Milli $Q$ water & - & - & 8.0 & - \\
\hline Extracted DNA(ng) & $50 \mathrm{ng}$ & $5-200$ & 1.0 & $\begin{array}{l}\text { Absence of amplification } \\
\text { at lower concentration } \\
\text { and presence of smear } \\
\text { at higher concentration }\end{array}$ \\
\hline $\begin{array}{l}\text { Taq DNA polymerase } \\
\text { (units/ } / \mathrm{L} \text { ) }\end{array}$ & one unit/ $\mu \mathrm{L}$ & $0.1-1.0$ & 1.0 & $\begin{array}{l}\text { Lower concentration led } \\
\text { to improper amplification } \\
\text { whereas increased } \\
\text { concentration showed } \\
\text { decreased specificity }\end{array}$ \\
\hline
\end{tabular}


Table 3: Quantification of DNA in different accessions of A. vasica

\begin{tabular}{|l|c|c|c|c|}
\hline \multirow{2}{*}{ A. vasica samples } & \multicolumn{2}{|c|}{ Optical density $(\boldsymbol{\lambda})$} & \multirow{2}{*}{$\begin{array}{c}\text { Ratio } \\
\mathbf{2 6 0 / 2 8 0} \mathbf{~ n m}\end{array}$} & $\begin{array}{c}\text { DNA } \\
\text { conc. }(\boldsymbol{\mu g} / \mathbf{m l})\end{array}$ \\
\cline { 2 - 5 } & $\mathbf{2 6 0} \mathbf{~ n m}$ & $\mathbf{2 8 0} \mathbf{~ n m}$ & 1.90 & 0.20 \\
\hline AVND & 0.04 & 0.021 & 1.85 & 0.25 \\
\hline AVKU & 0.05 & 0.027 & 1.89 & 0.35 \\
\hline AVNH & 0.07 & 0.037 & 1.81 & 0.10 \\
\hline AVCH & 0.02 & 0.011 & 1.80 & 0.45 \\
\hline AVBS & 0.09 & 0.05 & 1.87 & 0.15 \\
\hline AVSN & 0.03 & 0.016 & 1.87 & 0.45 \\
\hline AVDN & 0.09 & 0.048 & 1.84 & 0.15 \\
\hline AVPL & 0.03 & 0.038 & 1.87 & 0.45 \\
\hline AVDL & 0.09 & 0.048 & 1.94 & 0.35 \\
\hline
\end{tabular}

were previously optimized. PCR products were kept at $4^{\circ} \mathrm{C}$. Amplified PCR products were separated on $1.5 \%$ $(\mathrm{w} / \mathrm{v})$ agarose gel in $1 \mathrm{X}$ TAE buffer $(\mathrm{pH} 8.3)$ stained with Ethidium bromide in a final concentration of 10 $\mu \mathrm{g} / \mathrm{ml}$. Electrophoresis was performed at 90 volt for $2 \mathrm{~h}$ and then visualized the gel, photographed and analyzed. Gene ruler ${ }^{\mathrm{TM}} 1 \mathrm{~kb}$ DNA ladder (Bangalore Genei Pvt. Ltd.) was used as molecular size marker. The reproducibility of the amplification products was checked twice for each polymorphic primer. A control PCR tube containing all the components but no genomic DNA was run with each primer to check the contamination. The bands that did not show any fidelity were eliminated. Only reproducible fragments were scored while nonreproducible with the faintly stained fragments were discarded.

\section{Data analysis}

Evaluation of fragment patterns in RAPD analyses were analyzed using Nei genetic similarity index that determined the genetic distances between the genotypes of $A$. vasica. The co-efficient on $\mathrm{x}$ axis represented the similarity indices (DICE) of the different genotypes chosen in the current study. Reproducible bands were scored manually as 1 or 0 for the presence or absence of the bands across all the Adhatoda accessions for each primer. The pair wise genetic similarities among all pair of samples were estimated with Jaccard's co-efficient. ${ }^{14}$ The statistical analysis was carried out using NTSYSPC software (version 2.11s). ${ }^{15}$ RAPD analyses were analyzed using the Nei genetic similarity index ${ }^{16}$ on the basis of equation, $\mathrm{SI}=2 \mathrm{Nij} /(\mathrm{Ni}+\mathrm{Nj})$, Where $\mathrm{Nij}$ was the number of common bands shared between samples $\mathrm{i}$ and $\mathrm{j}, \mathrm{Ni}$ and $\mathrm{Nj}$ were the total no of DNA bands for genotypes $i$ and $j$, respectively. In order to group the genotypes into discrete clusters a dendrogram was constructed by employing UPGMA. ${ }^{17}$

\section{Reproducibility of amplifications patterns}

DNA amplifications with RAPD primer were repeated at least thrice to ensure reproducibility. The bands were considered reproducible and scorable only after observing and comparing them in three separate amplifications for each primer. Clear and intense bands were scored whereas faint bands against background smear got rejected and not considered for further analysis.

\section{Scoring and data analysis}

For each accession, each fragment/ band that was amplified using RAPD primers was treated as a unit character. Unequivocally scorable and consistently reproducible amplified DNA fragments were transformed into binary characters matrices ( 1 for presence, 0 for absence). The commercial software package NTSYS-PC ${ }^{15}$ was used to develop similarity matrices. These data were then used to construct dendrogram for cluster analysis based on un-weighted pair group method with arithmetic mean (UPGMA) using computer programme WINDIST. ${ }^{18}$

\section{RESULTS}

\section{Genetic diversity between accessions}

The similarity matrix of genetic distance was used to show the relationship amongst the ten accessions of A. vasica. Genetic variability studies in $A$. vasica collected from different locations of India had been carried out using RAPD markers. DNA was isolated by CTAB method. ${ }^{19}$ Measurement of absorbance at 260 $\mathrm{nm}$ and at $280 \mathrm{~nm}$ provided validation of the purity of nucleic acid in all the samples: A260/A280 ratios above 1.8 for DNA or 2.0 for RNA indicated pure samples; lower ratio values indicated the presence of protein or other contaminants. ${ }^{20}$ The ratios of optical density of $260 / 280$ of all samples found in the range of 1.7-1.9 


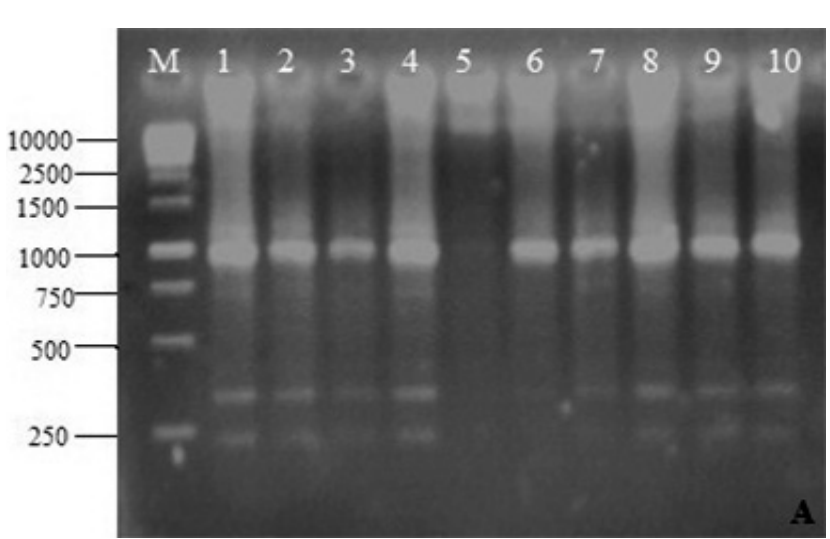

Figure 1: Gel picture showing the RAPD amplification patterns generated by OPA- 6

[M-Marker, Names of Samples: 1-New Delhi; 2-Hisar; 3-Kurukshetra; 4- Nahan; 5-Chandigarh; 6-Banaras; 7-Solan; 8-Dehradun; 9-Patiala; 10-Dalhousie]

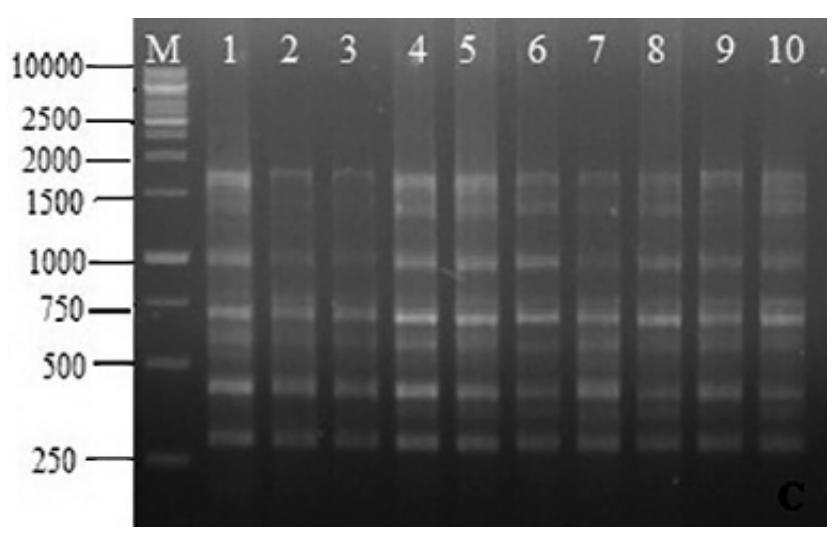

Figure 3: Gel picture showing the RAPD amplification patterns generated by OPA-11

[M-Marker, Names of Samples: 1-New Delhi; 2-Hisar 3-Kurukshetra 4- Nahan 5-Chandigarh 6-Banaras 7-Solan 8-Dehradun 9-Patiala 10-Dalhousie]

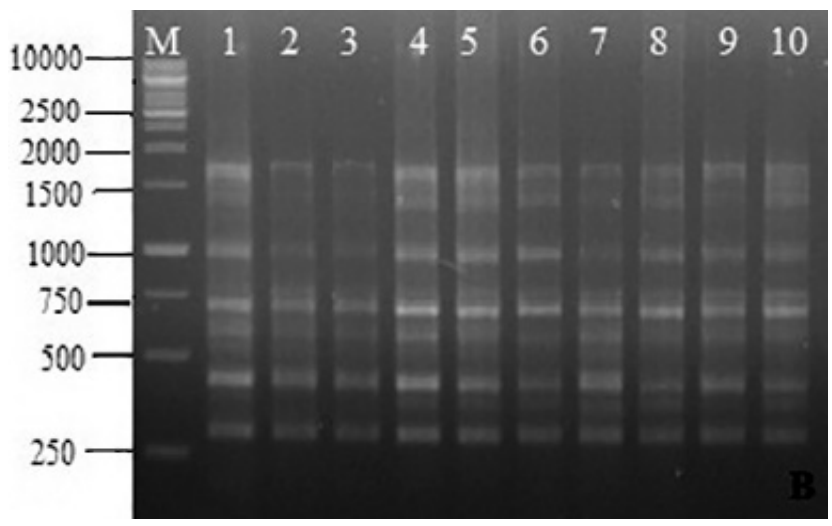

Figure 2: Gel picture showing the RAPD amplification patterns generated by OPA-7

[M-Marker, Names of Samples: 1-New Delhi; 2-Hisar; 3-Kurukshetra; 4- Nahan; 5-Chandigarh; 6-Banaras; 7-Solan; 8-Dehradun; 9-Patiala; 10-Dalhousie]

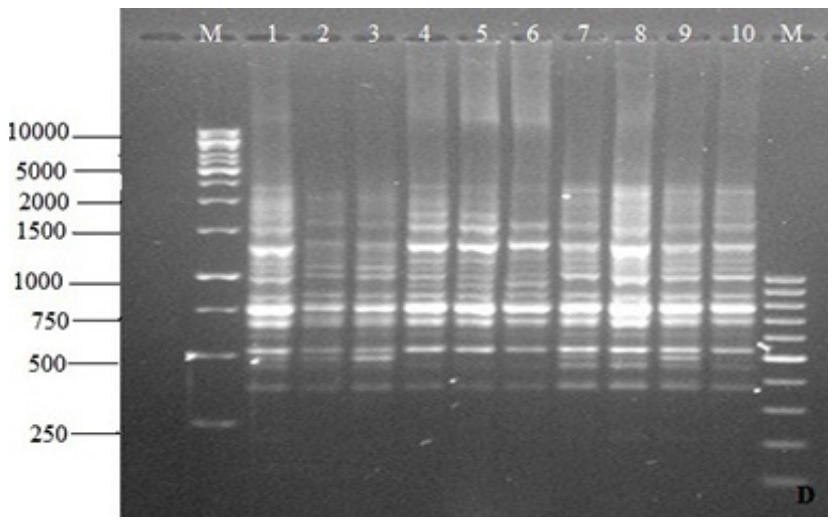

Figure 4: Gel picture showing the RAPD amplification patterns generated by OPA-12

[M-Marker, Names of Samples: 1-New Delhi 2-Hisar 3-Kurukshetra 4- Nahan 5-Chandigarh 6- Banaras 7-Solan 8-Dehradun 9-Patiala 10-Dalhousie]

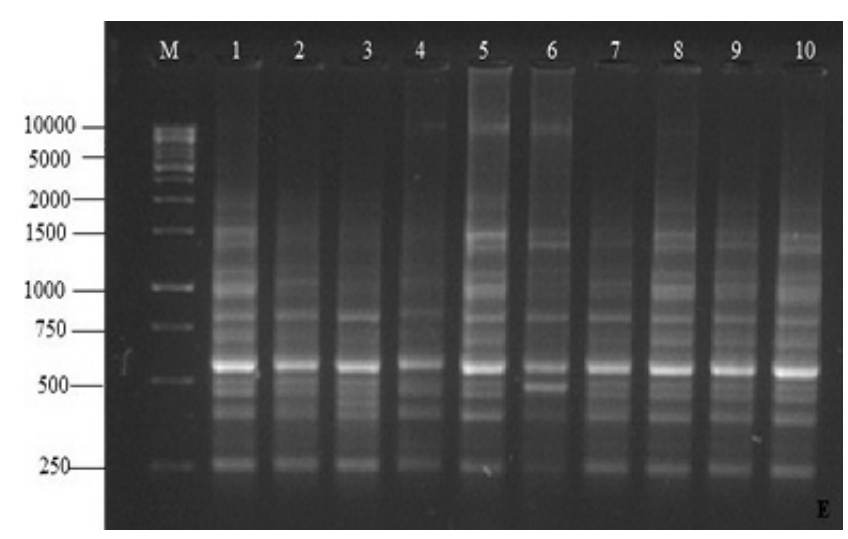

Figure 5: Gel picture showing the RAPD amplification patterns generated by OPA-18

[M-Marker, Names of Samples: 1-New Delhi 2-Hisar 3-Kurukshetra 4- Nahan 5-Chandigarh 6- Banaras 7-Solan 8-Dehradun 9-Patiala 10-Dalhousie]

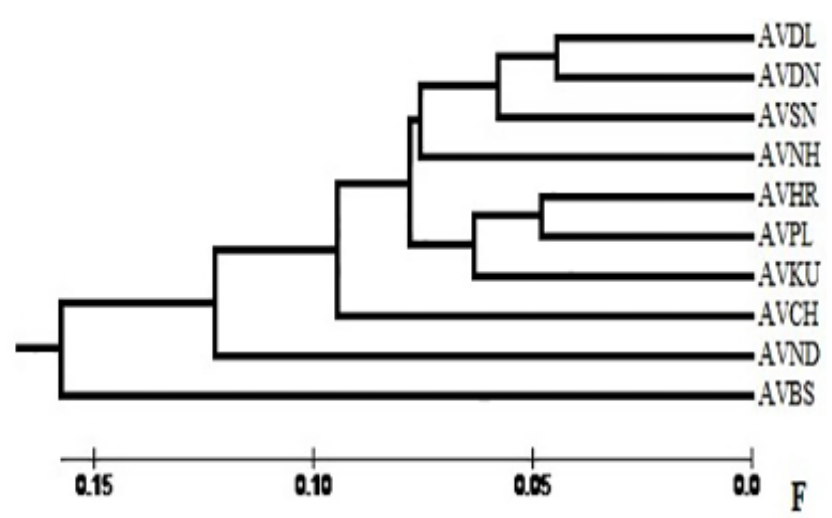

Figure 6: UPGMA dendrogram based on Dice (Nei and Li, 1979) method from RAPD data 
Table 4: RAPD primers data and the percent-age of polymorphic bands

\begin{tabular}{|c|c|c|c|c|c|c|c|c|}
\hline $\begin{array}{c}\text { Primer } \\
\text { Code }\end{array}$ & $\begin{array}{c}\text { Nucleotide } \\
\text { Sequence }\left(5^{\prime}-3^{\prime}\right)\end{array}$ & $\begin{array}{c}\text { Annealing } \\
\text { Temperature } \\
\operatorname{Tm}\left({ }^{\circ} \mathrm{C}\right)\end{array}$ & $\begin{array}{l}\text { Size of } \\
\text { fragments } \\
\text { (bps) }\end{array}$ & TNB & NPB & $\% \mathrm{P}$ & $\%$ M & UP \\
\hline OPA-01 & CAGGCCCTTC & $34^{\circ} \mathrm{C}$ & $375-1600$ & 117 & 38 & 32.47 & 59.82 & 3 \\
\hline OPA-02 & TGCCGAGCTG & $34^{\circ} \mathrm{C}$ & $300-1050$ & 100 & 50 & 50 & 50 & - \\
\hline OPA-03 & AGTCAGCCAC & $32^{\circ} \mathrm{C}$ & $390-1200$ & 85 & 15 & 17.64 & 82.35 & - \\
\hline OPA-04 & AATCGGGCTG & $32^{\circ} \mathrm{C}$ & $260-1500$ & 143 & 28 & 19.58 & 48.95 & 1 \\
\hline OPA-05 & AGGGGTCTTG & $32^{\circ} \mathrm{C}$ & $300-1550$ & 81 & 21 & 25.92 & 74.07 & - \\
\hline OPA-06 & GGTCCCTGAC & $34^{\circ} \mathrm{C}$ & $300-1900$ & 65 & 56 & 86.15 & 00 & - \\
\hline OPA-07 & GAAACGGGTG & $32^{\circ} \mathrm{C}$ & $450-1450$ & 54 & 45 & 83.33 & 00 & - \\
\hline OPA-08 & GTGACGTAGG & $32^{\circ} \mathrm{C}$ & $250-1400$ & 103 & 07 & 6.79 & 67.96 & - \\
\hline OPA-09 & GGGTAACGCC & $34^{\circ} \mathrm{C}$ & $250-1600$ & 85 & 30 & 35.29 & 11.76 & - \\
\hline OPA-10 & GTGATCGCAG & $32^{\circ} \mathrm{C}$ & $375-1750$ & 103 & 22 & 21.35 & 00 & - \\
\hline OPA-11 & CAATCGCCGT & $32^{\circ} \mathrm{C}$ & $350-1500$ & 93 & 93 & 100 & 00 & - \\
\hline OPA-12 & TCGGCGATAG & $32^{\circ} \mathrm{C}$ & $300-1800$ & 72 & 72 & 100 & 00 & - \\
\hline OPA-13 & CAGCACCCAC & $34^{\circ} \mathrm{C}$ & $360-1700$ & 165 & 19 & 11.51 & 00 & - \\
\hline OPA-14 & TCTGTGCTGG & $32^{\circ} \mathrm{C}$ & $380-1600$ & 102 & 23 & 22.54 & 68.62 & - \\
\hline OPA-15 & TTCCGAACCC & $32^{\circ} \mathrm{C}$ & $280-1150$ & 65 & 27 & 41.53 & 30.76 & 1 \\
\hline OPA-16 & AGCCAGCGAA & $32^{\circ} \mathrm{C}$ & - & - & - & - & - & - \\
\hline OPA-17 & GACCGCTTGT & $32^{\circ} \mathrm{C}$ & $380-1400$ & 56 & 17 & 30.35 & 53.57 & - \\
\hline OPA-18 & AGGTGACCGT & $32^{\circ} \mathrm{C}$ & $350-1550$ & 29 & 29 & 100 & 00 & 1 \\
\hline OPA-19 & CAAACGTCGG & $32^{\circ} \mathrm{C}$ & $325-1400$ & 36 & 27 & 75 & 00 & - \\
\hline OPA-20 & GTTGCGATCC & $32^{\circ} \mathrm{C}$ & $360-1750$ & 139 & 31 & 22.30 & 00 & - \\
\hline
\end{tabular}

TNB-Total number of bands; NPB- Number of polymorphic bands; UP- Unique Products; \%P- Polymorphism; \%M- Monomorphism

indicated high purity of DNA (Table 3). The co-efficient on $\mathrm{x}$ axis represented the similarity indices (DICE) of the different accessions chosen in the current study. The genetic distance between the studied accessions was illustrated by the UPGMA dendrogram (Figure 6). Of all the samples analyzed accessions AVBS was marked by the highest distance from the remaining accessions. The most similar accessions were found to be AVDL and AVDN followed by from AVHR and AVPL. The values of Nei's genetic similarity validated the above findings. The genetic similarity derived from the data of RAPD marker for analysis all the accessions varied from 0.60 between AVSN and AVBS to 0.91 between AVDN and AVDL.

\section{Level of polymorphism}

To assess the genetic diversity of A. vasica, samples were collected from different regions in India and twenty random declaimer primers were used to amplify the genomic DNA isolated from the leaves and out of them five primers OPA-06, OPA-07, OPA-11, OPA-12, OPA-18 (Figures 1-5) showed the maximum of polymorphism. These primers generated total of 313 fragments of which 295 (94\%) were polymorphic exhibiting a high degree of diversity amongst the accessions. The high level of polymorphism observed in the pres- ent material was similar to that observed in studies of Mangifera indica ${ }^{21}$, Olea europea ${ }^{22}$ and Malpighia glabra Linn. ${ }^{23}$ Primers (OPA 1-OPA 20) employed exhibited a wide variation in polymorphism ranging from $0-100 \%$ (Table 4). This was understandable as product amplification depends upon the sequence of random primers and their compatibility with genomic DNA. The number of markers detected by each primer found to be dependent on primer sequence and the extent of genetic variation, which was genotype specific. ${ }^{24}$ Out of the 20 primers used 8 of them gave satisfactory and reproducible amplification patterns exhibiting high degree of polymorphism as shown below in Figures 1-5 where OPA were operons and employed here as RAPD primers for carrying out the amplification of DNA in powdered leaf samples of $A$. vasica; $M$ denoted the Molecular marker as $1 \mathrm{~kb}$ ladder and 1-10 denoted the different accessions of vasaka collected from different geographical locations.

\section{Dendrogram analysis}

The similarity matrix representing Jaccard's coefficient was used to cluster the data following the UPGMA algorithm. To estimate the potential of individual primers for the characterization of variability in A. vasica, data obtained from the individual primers were 


\begin{tabular}{|c|c|c|c|c|c|c|c|c|c|c|}
\hline \multicolumn{8}{|c|}{ Table 5: Dice similarity coefficient for RAPD data: Dice (Nei and Li, 1979) } \\
\hline & $\mathbf{1}$ & $\mathbf{2}$ & $\mathbf{3}$ & $\mathbf{4}$ & $\mathbf{5}$ & $\mathbf{6}$ & $\mathbf{7}$ & $\mathbf{8}$ & $\mathbf{9}$ & $\mathbf{1 0}$ \\
\hline $\mathbf{1}$ & 1.000 & & & & & & & & \\
\hline $\mathbf{2}$ & 0.854 & 1.000 & & & & & & & \\
\hline $\mathbf{3}$ & 0.757 & 0.834 & 1.000 & & & & & & \\
\hline $\mathbf{4}$ & 0.867 & 0.806 & 0.705 & 1.000 & & & & & \\
\hline $\mathbf{5}$ & 0.841 & 0.771 & 0.770 & 0.870 & 1.000 & & & & \\
\hline $\mathbf{6}$ & 0.715 & 0.694 & 0.739 & 0.660 & 0.754 & 1.000 & & & \\
\hline $\mathbf{7}$ & 0.789 & 0.871 & 0.735 & 0.786 & 0.737 & 0.605 & 1.000 & & \\
\hline $\mathbf{8}$ & 0.848 & 0.853 & 0.716 & 0.882 & 0.813 & 0.644 & 0.863 & 1.000 & \\
\hline $\mathbf{9}$ & 0.890 & 0.903 & 0.809 & 0.834 & 0.828 & 0.711 & 0.874 & 0.906 & 1.000 & \\
\hline $\mathbf{1 0}$ & 0.829 & 0.821 & 0.709 & 0.885 & 0.814 & 0.635 & 0.848 & 0.911 & 0.876 & 1.000 \\
\hline
\end{tabular}

1-New Delhi 2- Hisar 3-Kurukshetra 4-Nahan 5-Chandigarh 6-Banaras 7- Solan 8-Dehradun 9-Patiala 10-Dalhousie

processed separately (not shown). Different primers grouped the accessions in two major clusters. The dendrogram constructed for pooled data showed two major clusters. The dendrogram (Figure 6) based on SI (Table 5) showed distinct separation of the collected accessions though morphologically they were similar and inseparable. All the accessions were found in one cluster except AVBS while it was found in other cluster. The accessions which were found in another cluster were further sub divided into sub-clusters comprising of all the accessions except AVKU. The sub-cluster formed comprised of $\mathrm{AVCH}$ and was further subdivided into two trunks that in turn sub divided into upper sub cluster 1(USC1) and lower sub cluster 1 (LSC1). USC I comprised of collections from AVDN, AVDL, AVNH, AVND and the LSC I comprised of accessions from AVHR, AVPL, and AVSN. AVBS was marked by highest genetic distance from other accessions and hence clearly separated from them.

\section{DISCUSSION}

Due to easiness, rapidity and simplicity the RAPD technique has been used widely for differentiating a large number of medicinal species from their close relatives or adulterants including Panax species, ${ }^{25}$ Coptis species, ${ }^{26}$ Astragalus species, Lycium barbarum L., ${ }^{27}$ Panax ginseng $^{28}$ and Echinacea species. ${ }^{29}$ These characters were especially advantageous for the identification of any herbal drug because of little DNA existing in the dried material. The significance of present work was mainly focused in differentiating genuine samples from the adulterated ones and to establish the level of genetic relatedness between them as our RAPD marker proved to be easily reproducible under wide variation of amplification conditions. Results were not affected at all with the changes in the origin of primer, the taq polymerase and the thermal cycler used in the experiment.
Various accessions of $A$. vasica collected from various locations as described earlier were subjected to RAPD studies as the same had already been found to be useful in differentiating the accessions of Taxus wallichiana, Juniperus communis L, Allium schoenoprasum L, Andrographis paniculata collected from different geographical regions. High degree of polymorphism was exhibited by the vasaka accessions and this might be attributed due to deletion, addition, substitution of base within the priming site sequence ${ }^{10}$ and this was in accordance with previously reported findings by Deshwal et al., 2005 as he reported 14 (58\%) polymorphic primers with 73 amplification products in Neem accessions. ${ }^{30}$ The number of polymorphic primers and fragments generated may vary as product amplification depends upon the sequence of random primers and extent of genetic variations which in turn is genotype specific. ${ }^{24}$

We reported the genetic diversity values in the range of 0.60 - 0.91 in A.vasica. The range of genetic diversity values broadly indicated the degree of heterogeneity and homogeneity in different accessions of plant species. ${ }^{31}$ The samples from AVBS and AVSN showed significant genetic diversity with similarity co-efficient value of 0.60 followed by that of collections from AVBS and AVDL. This was understandable as these samples were located far apart $(>2500 \mathrm{~km})$, at different altitudes and belonging to two different geographical regions clearly showed that the climatic conditions and physical parameters might affect the plant genome and as the plant was adapted and these changes were inherited through genome to next generation. However the accessions AVDL and AVDN collected from Dalhousie and Dehradun displayed the maximum genetic similarity with a similarity co-efficient value of 0.91 followed by collection from AVHR and AVPL locations clearly stated the fact that collections from the almost similar altitudinal heights and geographical locations possess almost similar characteristics. The dendrogram obtained also estab- 
lished the genetic relatedness among different accessions and separated all the accessions with the exceptions of AVDL and AVDN, AVHR and AVPL and thus considered as closely related genetically.

The gene diversity in $A$. vasica was comparatively of narrow range $(0.60-0.91)$ with higher mean gene diversity value. The higher mean gene diversity could be explained as the samples were collected from different altitudes located at different geographical locations. Despite the collections from varying altitudes $A$. vasica showed somewhat lower range of genetic diversity which implied conservation of germplasm and lower level of heterogeneity. One of the possible reasons may be that the species has been endangered by human interventions. ${ }^{32}$ The collections from AVSN and AVBS showed a significant genetic diversity between them with a co-efficient value of 0.60 . This is understandable as these samples were located far apart $(>2500 \mathrm{~km})$ at different altitudes and belong to different geographical locations clearly showed that the climatic conditions and physical parameters might affect the plant genome as the plant was adapted and these changes were inherited through one genome to next generation.

Based on the above findings there were the collections comprising of both high as well as low similarity indexes. High similarity indices suggested that the individuals in the population had close genetic relationship among them that in turn was reflection of adaptation to environment and beneficial to propagation, resources conservation and domestication of wild species. This situation could arise in natural populations where there was a possibility of free/random pollen flow and fertilization. The genetic similarity was closely related with their geographical locations. ${ }^{33}$ However, Cluster analysis had clearly indicated that there was eco-geographical isolation between the samples collected from different locations as sometimes even the geographically isolated individuals tend to accumulate genetic variations during the course of environmental adaptations. $^{34}$

\section{REFERENCES}

1. Anjaria J, Bhatt G. A glossary of selected indigenous medicinal plants of India. Nature Heals. Ahmadabad: SRISTI; 1995. 11.

2. Ali M. Text book of Pharmacognosy. $2^{\text {nd }}$ Edn. New Delhi: CBS publication; 1998. 355-6.

3. Atal CK. Chemistry and pharmacology of vasicine: Anew oxytocic and abortifacient. Jammu Tawi: India Regional Research Laboratory.1980; 1(1): 93-103.

4. Shinawie A. Wonder drugs of medicinal plants: Ethnobotany. Mol Cell Biochem. 2002; 213(1-2): 99-109.

5. Dymock W. Indian Pharmacographia of plants. Hamdard National Foundation Pak. 1972; 3: 343-44.

6. Ayensu ES. World medicinal plant resources. In conservation for productive agriculture (eds Chopra VL and Khooshoo TN). New Delhi: ICAR; 1986.

7. Katwal RPS, Srivastava RK, Kumar S, Jeeva V. State of forest genetic resources conservation and management in India. 2003. Indian Council
The present study suggested that RAPD is appropriate for the analysis of genetic variability in closely related genotypes. Moreover it could differentiate the plants collected from distant places belonging to same agroclimatic sub zones.

\section{CONCLUSION}

The present study confirmed the suitability of RAPD as a reliable, simple, easy to handle and as an elegant tool in molecular diagnosis of different accessions of $A$. vasica. RAPD hereby proved to be useful in molecular profiling of different accessions of $A$. vasica. The variations observed in the genetic diversity could be due to the use of random primers as well as the variations that naturally occur in the genotypes. The high amount of polymorphism (\%) observed in the study could also be due to inclusion of vasaka genotypes with popping and non-popping characters.

The low level of genetic diversity observed in different accessions suggested the regional approach for the conservation of $A$. vasica. The species or at least a large part of its genetic diversity may be lost in the near future due to its medicinal and other uses and its consequent exploitation if appropriate conservation measures are not adopted. Since single or even a few plants will not represent the whole genetic variability in Adhatoda, there appears to be a need to maintain sufficiently large populations in natural habitats to conserve genetic diversity and to avoid genetic erosion.

\section{CONFLICT OF INTEREST}

The authors confirms that this article has no conflict of interest.

\section{ACKNOWLEDGEMENT}

Authors are thankful to Bioactive Natural Product Laboratory for providing the necessary facilities for carrying out the studies.

of forestry Research and Education and Forest Resources development Service working paper FGR/65E, Forest resource division FAO, Rome, Italy http://www.fao.org/document/show_cdr.asp?url_file=/docerp/007ad871e/ ad871e00htm

8. Satakopan S, Thomas PJ. Note on adulterant of vasaka. Indian J Pharm. 1970; 32(3): 66-7.

9. Cosyns JP, Jadoul M, Squifflet JP, Wese FX, Van Ypersele DS. Urothelial lesions Chinese herb nephropathy. American J kidney Disease 1999; 33(6): 1011-17.

10. Williams JGK, Kubelik AR, Livak KJ, Rafalski JA, Tingey SV. DNA polymorphism amplified by arbitrary primers is useful as genetic markers. Nucleic Acids Res. 1990; 18(22): 6531-5.

11. Mondini L, Noorani A, Pagnotta MA. Assessing plant genetic diversity by molecular tools. Diversity 2009; 1(1): 19-35. 
12. Weish J, Mc Clelland M. Fingerprinting genomes using PCR with arbitrary primers. Nucleic Acid Res. 1990; 18(24): 7213-8.

13. Ashley MV, Dow BV. The use of microsatellites for the genetic analysis of the natural population, in Molecular ecology and evolution: approaches and applications, edited by B Schierwater, B Streit, GP Wagner and R DeSalle (Birkhauser, Basel: Verlag; 1994; 185-281.

14. Jaccard P. Nouvelles researches surla distribution florale. Bull Soc Vaud Sci Nat. 1908; 44: 223-70.

15. Rohlf FJ. Numerical taxonomy and multivariate analysis system version 2.11 manual. New York: Applied biostatistics Inc; 2000.

16. Nei M, Li WH. Mathematical models for studying genetic variation in terms of restriction endonucleases. P Natl Acad Sci USA. 1979; 76(10): 5269-73.

17. Sneath PHA, Sokal R. Numerical Taxonomy. San Francisco: WH Freeman; 1973.

18. Yap IV, Nelson RJ. Winboot: a program for performing bootstrap analysis of binary data to determine the confidence limits of UPGMA- based dendrograms. IRRI Disc Ser No. 14. Phillipines: Int Rice Res Inst Manila; 1996.

19. Doyle JJ, Doyle JL. Isolation of plant DNA from plant tissues. Focus 1990; 12: $13-5$.

20. Gallagher SR. Quantitation of DNA and RNA with absorption and fluorescence spectroscopy. 3.9-3.15. FA Ausubel FAR, Brent RE, Kingston DD, Moore JG, Seidman JA, K Smith and Struhl. Current Protocols in Molecular Biology. John Wiley \& Sons publications; 1989.

21. Karihaloo JL, Dwivedi YK, Archak S, Gaikwad AB. Analysis of genetic diversity of Indian mango using RAPD markers. J Hortic Sci Biotechnol 2003; 78(3): 285-98

22. Belaj A, Satovic Z, Rallo R, Trujillo R. Genetic diversity and relationship in olive (Olea europaea) germplasm collections as determined by randomly amplified polymorphic DNA. Theor Appl Genet 2002; 105(4): 638-44.

23. Chowdhury AK, Srinivas P, Tongpamnak P, Saksoong P. Genetic diversity based on morphology and RAPD analysis in vegetable soyabean. Korean J Crop Sci. 2001; 46(2): 112-20.
24. Upadhyay A, Jayadev K, Manimekalai R, Parthasarathy VA. Genetic relationship and diversity in Indian coconut accessions based on RAPD markers. Scientia Hortic 2004; 99(3): 353-62.

25. Shaw PC, Butt PPH. Authentication of Panax species and their adulterants by random primed polymerase chain reactions. Planta Med. 1995; 61(05): 466-9.

26. Cheng KT, Chang HC, Su CH, Hsu FL. Identification of dried rhizomes of coptis species using random amplified polymorphic DNA. Bot Bull Acad Sin 1997; 38: 241-4.

27. Cheng $\mathrm{KT}$, Chang $\mathrm{HC}$, Huang $\mathrm{H}$, Lin CT. RAPD analysis of Lycium barbarum medicine in Taiwan market. Bot Bull Acad Sin. 2000; 41: 11-4.

28. Um J, Chung $\mathrm{H}, \mathrm{Kim} \mathrm{M}$, et al. Molecular authentication of Panax ginseng species by RAPD analysis and PCR-RFLP. Bio Pharmaceut Bull 2001; 24(8): 872-5.

29. Nieri P, Adinolfi B, Morelli I, Breschi MC, Simoni G, Martinotti E. Genetic characterization of three medicinal plant Echinacea species using RAPD analysis. Planta Medica. 2003; 69(07): 685-6.

30. Deshwal RPS, Singh R, Malik K, Randhawa GJ. Assessment of genetic diversity and genetic relationships among 29 populations of Azardiracthta indica A. Juss using RAPD markers. Genet Resour Crop Evol. 2005; 52(3): 285-92.

31. Sarawat M, Das ES. Analysis of genetic diversity ISSR and RAPD markers herb. Plant Cell Rep. 2008; 27(3): 519-28.

32. Sayed M, Hassan Z, Mohammed shafie B, Shafie, Shah RM. Analysis of random amplified polymorphic DNA (RAPD) of Artemisia capillaries (worm wood capillary) in east cost of peninsular Malyasia World. Appl Sci J. 2009; 6(7): 976-86.

33. Schaal BA, Haryworth, Olsan KM, Rauscher JT, Smith WA. Phylogeographic studies in plants: Problems and perspectives. Mol Ecol. 1998; 7(4): 465-74.

34. Williams JGK, Kubelik AR, Livak KJ, Rafalski JA, Tingey SV. DNA polymorphism amplified by arbitrary primers are useful as genetic markers. Nucleic Acids Res. 1990; 18(22): 6531-5. 